\title{
A new approach for a renewed flood risk management in Flanders; the pilot case of the Maarkebeek catchment
}

\author{
Neel Devroede ${ }^{1}$,a, Annelies Huyck ${ }^{2}$, Joost Dewelde ${ }^{1}$, Michel Craninx ${ }^{1}$ and Sven Verbeke ${ }^{3}$ \\ ${ }^{1}$ Flanders Environment Agency, Koning Albert-Il laan 20 bus 16, 1000 Brussels, Belgium \\ ${ }^{2}$ Flanders Environment Agency, Raymonde de Larochelaan 1, 9051 Ghent, Belgium \\ ${ }^{3}$ Flanders Environment Agency, Zandvoordestraat 375, 8400 Ostend, Belgium
}

\begin{abstract}
Based on the results of recent studies a renewed vision for flood risk management in Flanders took shape under the name of multi-layered water safety. The multi-layered water safety aims at reducing flood risk to a socially and economically acceptable level through an optimal mix of protective, preventive and preparedness measures, in which all actors in flood risk management face up to their responsibility. A new approach to develop a flood risk action plan based on the vision of multi-layered water safety was applied to the pilot case of the catchment of the Maarkebeek. Using a methodology based on quantitative economic as well as social risk values, potential measures are assessed taking climate change and land use projections into account. Measures and combinations that have a positive (or marginally but acceptable negative) cost-benefit ratio and a large social benefit are retained. These serve as a starting point for the debate on flood risk management with all the actors and for the consultation of the stakeholders. As a result of several actor meetings a 'river contract' was drafted. The river contract is a commitment of all actors to realise the listed measures, securing the collaborative effect. The river contract is an integrated response to the flood risk problem at catchment scale and aims at providing solutions to all affected households. This approach, applying multi-layered water safety to a local river catchment, combines an objective model-based assessment with intense stakeholder deliberation resulting in a widely accepted and objectively effective action plan i.e. the river contract, to manage flood risk in an efficient and sustainable way.
\end{abstract}

\section{Introduction}

In the previous century, flood management was the sole responsibility of the water managers. They designed and applied technical engineering measures, such as dikes, embankments, deepening, widening and straightening of rivers, etc. to control the flood hazard. Hydrological and hydrodynamic modelling was used to determine the most effective measures. The main concern was to ensure that the water flows into the sea as quickly as possible. As a result natural flood plains were cut off from the river's dynamics and exploited for construction. However, there was a less positive side to this policy. The increase of paved surfaces prevented water from infiltrating. The increased runoff even exacerbated by the widened and straightened rivers, create floods further downstream where the options for flood control are often limited.

In more recent decades an evolution took place to the so-called '3-steps-strategy: retain-store-discharge', embedding mitigation measures in flood management in Flanders. The sequence of these measures indicates their priority. In the first place this principle aims at retaining excess rain where it falls by maximal re-use, infiltration and delayed discharge. The local storage of water in the valley is the next best option. Discharging water in a

\footnotetext{
a Corresponding author: $\underline{\text { n.devroede@ } @ v m m . b e}$
}

controlled way has the lowest preference as it may shift the problem of flood further downstream. Large investments in these protective measures reduced the impact of flooding significantly. However, Flanders is still a flood-prone region and experienced multiple floods with significant damages, even in the recent years. One of the last major floods, in November 2010, affected over 4000 buildings and caused a total damage of around 120 million EUR.

Additionally, Flanders is also known for its high degree of urbanization which is expected to increase still [1]. This will result in a higher surface water runoff increasing the likelihood of flooding. Moreover the impact of future flood can increase significantly if these additional constructions are built in flood-prone areas. Climate change projections indicate a probable significant increase in rainfall intensities and frequencies, particularly in the winter.. Both climate and land use change can thus contribute to a higher flood risk in Flanders in the future [2-7].

In a densely populated area such as Flanders it becomes more and more difficult to realize large protective infrastructure because of lack of space or public protest.

All these arguments made clear that a merely protective flood management will not suffice to cope with 
the current and future challenges of floods in Flanders. A flood risk management plan dealing with more and other measures is needed. Furthermore, it becomes clear that other parties such as spatial planning agencies, landowners and citizens need to be more involved in future flood risk management.

\section{Multi-layered water safety}

\subsection{Origin}

With the directive 2007/06/EC of the European parliament and of the Council of 23 October 2007 on the assessment and management of flood risks, commonly known as the 'Floods Directive', the focus moved from flood hazard management to flood risk management. Risk is defined as the combination of the likelihood of flooding and the potential adverse consequences. The Floods Directive requires the Member States to develop flood risk management plans (FRMP) containing measures to reduce flood damage to human health, the environment, cultural heritage and economic activity taking climate change and cost efficiency into account. The management plans have to account for all aspects of flood risk management focusing on prevention, protection and preparedness.

In 2009 the Flemish Environment Agency has commissioned an extensive study in which an evaluation framework is elaborated for all challenges Flanders faces in regard to an efficient and integrated flood risk management. In collaboration with engineering consultants Flanders Environment Agency has developed a methodology to quantify the impact of climate change, land use evolutions and possible measures using economic and social risk maps [8,9]. These maps are produced using a chain of statistical, numerical and mathematical models.

The methodology was applied to a total of 47 catchment areas in Flanders. The results proved that the most effective set of measures for risk reduction in Flanders is a combination of preventive, protective and preparedness measures. Investments in protective measures are still necessary as they can significantly reduce the flood risk in areas with high flood risk. (Flood forecasting and warning systems (preparedness) are almost always a cost-effective investment and also prevention showed to be essential for an effective flood risk management in Flanders. Almost in every assessed catchment a combination of all three types of measures was the best and optimal solution for efficient flood risk reduction.

\subsection{Principles}

The results of this study lead to a new vision on flood risk management in Flanders, which is defined as multilayered water-safety $[10,11]$. The principles of the Flemish multi-layered water safety are illustrated in figure 1. Multi-layered indicates that multiple types of measures are necessary to realize an acceptable level of water-safety. A combination of protective, preventive and preparedness measures, also '3P-measures', is almost always the most efficient way to reduce the flood risk in any Flemish catchment. Protective measures, including mitigation, reduce the likelihood of flooding. In areas with a high flood risk they are still an cost-effective solution. Preventive measures reduce the potential damages by reducing the vulnerability to flooding. This can be done by avoiding new risk receptors in flood prone areas (building freeze or flood resilient design) and by adapting buildings to be flood resilient using property level flood protection measures. Preparedness measures, including raising risk awareness and flood forecasting and warning systems reduce the real, actual damages by allowing appropriate action to be taken in time to reduce the exposure to the floodwater. Depending on the local situation one type of measure can be more dominant but only the combination of all 3P-measures can realize the objective of a sustainable and efficient reduction of flood risk in Flanders.

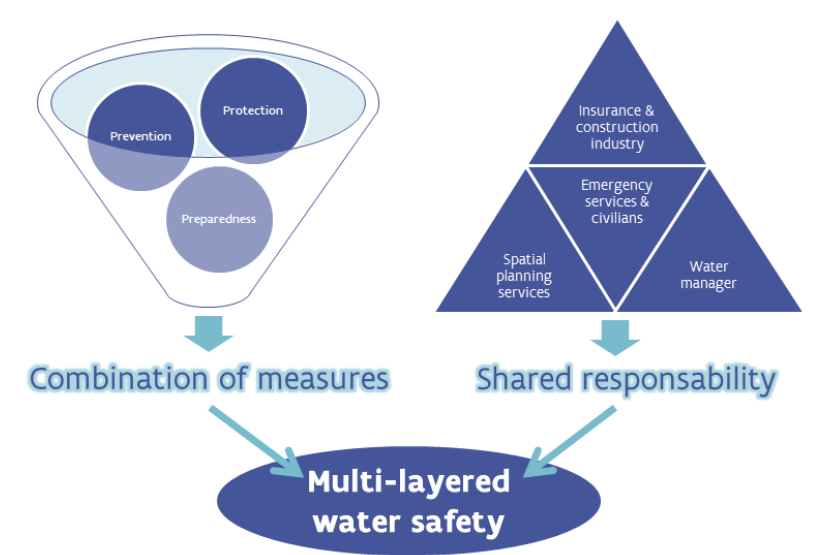

Figure 1. Schematization of the principles of the Multilayered water safety

The choice for a combination of protective, preventive and preparedness measures for flood risk management in Flanders is also a choice for a shared responsibility. Many of the responsibilities for realizing these new protective, preventive and preparedness measures are not the competence of the water managers. Regional and local spatial planners, emergency services, insurers and citizens are also involved and responsible.

\section{River contracts}

Because of the new collective responsibility, and the fact that the effectiveness of measures is often interdependent, the selection and planning of measures needs a different approach than before. Before, the water managers would make a plan and, after informing local actors, execute the chosen measures. Now, participation from all competent actors is necessary to come to a wellsupported, committed and effective set of measures.

For this reason Flanders Environment Agency introduced the concept of river contracts. A river contract is an action plan describing all agreed measures, in line with the multi-layered water safety, to deal with the flood risk within a certain catchment. Starting from the results 
of a model-based assessment, which is an advanced engineering approach, the measures are selected, further specified and extended in cooperation with local actors and stakeholders. The river contract is a commitment of all actors to realize those listed measures, securing the collaborative effect. The river contract is an integrated response to the flood risk problem at catchment scale and aims at providing solutions to all affected households.

\section{The pilot case of the Maarkebeek}

\subsection{Situation}

The Maarkebeek catchment measures $54 \mathrm{~km}^{2}$ and is part of the larger catchment of the Bovenschelde (the upper part of the Scheldt). The catchment is mainly situated in the south of the province Oost-Vlaanderen in Flanders, Belgium. Only its source lies in Flobecq in Wallonia (figure 2). After $13 \mathrm{~km}$ and passing 2 municipalities, Oudenaarde and Maarkedal, the Maarkebeek river flows into the Bovenschelde.

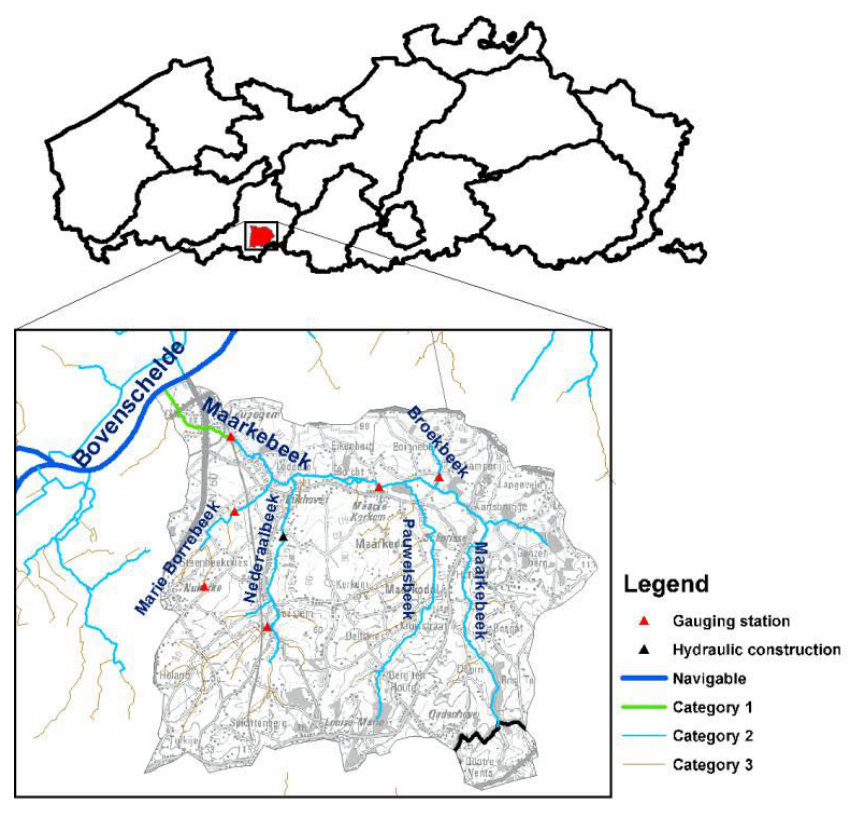

Figure 2. Geographic situation of the Maarkebeek catchment in Flanders.

The Maarkebeek is characterized by several water mills and a large biodiversity. It has relatively steep valleys causing its rivers to respond quickly to rainfall events. Mean discharges measure about $0.4 \mathrm{~m}^{3} / \mathrm{s}$, while maximum discharges of more than $25 \mathrm{~m}^{3} / \mathrm{s}$ are registered.

The Maarkebeek catchment has always been an area sensitive to flooding with 'hot-spots' flooding every 2 years. During the November 2010 flood event, the last major flood in Flanders, the Maarkebeek catchment was one of the most severely affected areas in Flanders. About 120 houses were flooded in the downstream part of the catchment, despite of the presence of a retention basin on the Nederaalbeek, one of the major affluents of the Maarkebeek.

The last severe event in the catchment occurred in November 2013. By that time, an embankment to protect
40 houses near the Maarkebeek was almost completed and successfully protected this area. The Maarkebeek catchment is also included in Flanders flood forecasting and warning systems allowing local emergency services to be prepared in case of imminent flood events.

Several studies from the past concluded that not enough cost-effective protective measures could be found to deal with the flood problem in the catchment. The downstream, flood-sensitive part is highly urbanized with little space left for water retention. The only open space left in that downstream area is likely to be built on as part of it is owned by a property developer. Since 2014 these parcels are classified as a 'signal area'. This indicates that the current assignation of use (residential development) is in conflict with the water system and further investigation is needed to evaluate the possible future development of the area.

Plans were made to build 4 more water retention basins: 3 on the Maarkebeek near 3 water mills and 1 on an affluent, the Pauwelsbeek. However, these measures are not all cost-effective, nor sufficient to protect all of the houses affected in the past.

Hence, the Maarkebeek catchment, along with 3 other catchment areas, was chosen as a pilot project to set up a first river contract through a process of stakeholder involvement.

\subsection{Engineering approach}

In the early stages of the process a model-based impact assessment of possible measures was done. The methodology was based on the evaluation framework elaborated by Blanckaert et al. (2012), and mentioned before in paragraph 2.1. with slight adaptations to fit the smaller scale of a catchment specific assessment.

The evaluation of potential measures against flooding was based on economic and social quantitative risk values. Climate change and land use projections were considered to account for the benefits on the long term. Measures that have a positive cost-benefit ratio are retained. Also measures with a minor negative costbenefit ratio but large social benefits are accepted because of the uncertainties in the impact assessment and the fact that non-economic benefits are not taking into account in the cost-benefit calculations.

The analysis showed that a number of protective measures such as the construction of 3 retention basins in the upstream valley and the construction of two retaining walls have a large benefit but slightly negative costbenefit ratio (figure 3). The most downstream part of the river proved to be a bottleneck and the cause of a high flood risk in this area and just upstream. Therefore deepening and widening of the downstream river segment and the replacement or removal of several obstructing bridges was also found to be cost-effective. However, these measures are dependent on the success of reassigning a new use to the 'signal area'. Recent modelling of the Maarkebeek catchment using advanced techniques revealed an additional pressure point. At the $\mathrm{N} 60$, near the outlet of the catchment (figure 3) water is pushed up by the bridge during high flow events and 


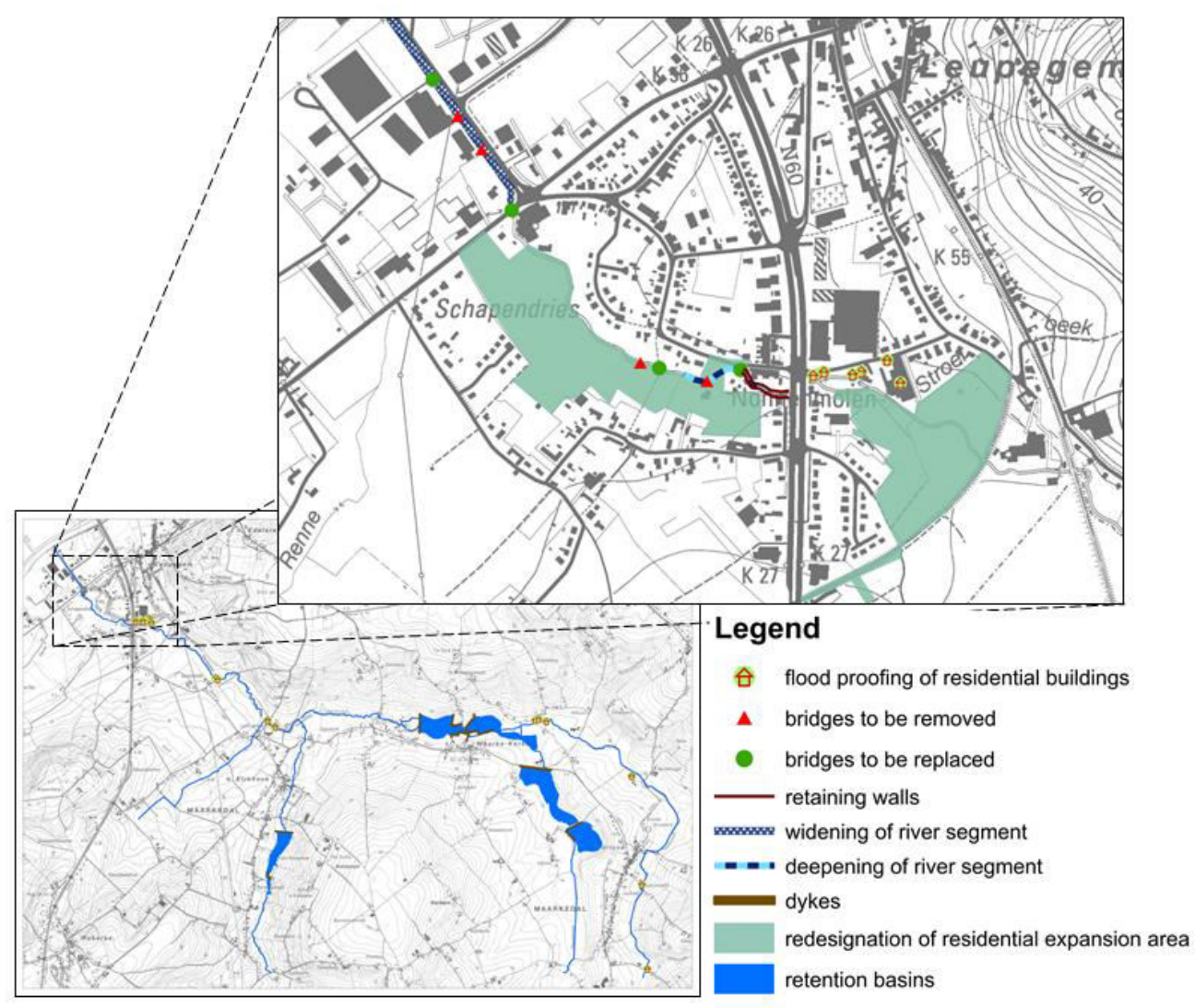

Figure3 Geographical overview of the measures in the Maarkebeek river contract

flows onto the road. From there it flows along the road and streets into residential areas and can get round the retaining wall, undoing the protective effect of the walls. Therefore the list of measures is extended with the purchase of a mobile dam by local emergency services to guide the water from the road back into the riverbed. Finally the analysis also revealed that not all houses could be protected against any flood at a reasonable price. At the property level citizens should be encouraged to take steps in making their homes or businesses less vulnerable to flooding by for example waterproofing external walls, installing flood barriers at door openings, installing a submersible pump to remove any flood water seeping in, ....

\subsection{Involving the actors}

This analysis served as the starting point for the debate with all actors and the consultation of the stakeholders. In a first step the province, responsible for the management of the upper part of the Maarkebeek and its tributaries, was contacted to evaluate and discuss the list of measures. From this meeting an number of infrastructural, protective measures were approved to be executed. The execution of many of these measures was dependent on the reassignment of a new use to the 'signal area' in the downstream part. It was however unclear which authority (regional, provincial or municipal) was responsible for taking the lead in this reassignment process and covering the associated costs. After a few consultations the province agreed to take initiative in the reassignment process and suggested to include this in a wider-scoped project on the development of a new spatial vision for the entire valley. In the latter step the local municipalities were also involved and were closely associated in the continuing process.

And in a last stage of the process also the local residents were consulted by means of an 'infomarket'. They were informed about the provisional list of agreed measures to reduce the flood risk in their region and they had the opportunity to respond and give their opinion and views about the problems and how to solve them. They were also informed about the following process for the development of a new spatial vision for the entire valley by the province and they were invited to take part. The on-going process for the development of the spatial vision for the entire valley is not further discussed in this paper.

As a result of these actor meetings a 'river contract' was set up containing the list of agreed measures and the commitment of all responsible actors. In the case of the Maarkebeek catchment the river contract includes the assignment of a new use for a flood prone residential expansion area, the construction of 3 retention basins, the deepening and widening of the downstream river segment, the replacement or removal of several obstructing bridges, the construction of two retaining walls, the flood proofing of several residential buildings, and the purchase of a mobile dam by local emergency services. The river contract also stipulates the following procedure to develop the spatial vision for the valley. A geographical overview of the agreed measures is given in figure 3 . 
The river contract was signed on December 1st of 2015 by the Flemish Environment Agency, the province of Oost-Vlaanderen, the municipality of Maarkedal and the city of Oudenaarde.

\section{The next pilot cases}

Because of the urgency for reducing the flood risk in the Maarkebeek catchment, the river contract focused on the flood risk management measures and served as a starting point for further developing a vision for the catchment area. For the future it is the intention to integrate both processes into one. Participation from all actors in the complete process from step one is intended. It is believed that by including as many stakeholders as possible from an early stage on, although it may lengthen the process, it will lead to the creation of a wellsupported action-plan. The evolution of the process will be strongly dependent on area specific characteristics.

For the next pilot, the Kerkebeek catchment, the process was started in the spring of 2016. In a first step, a steering committee, including all official stakeholders, sets out the scope of the public participation process. A charter is drawn up, identifying the needs and opportunities in the catchment. The charter is a first commitment on principle of all official stakeholders. The next step is to put out a tender for the counseling in the complex participation process It is the intention to start with the process for the Kerkebeek catchment, in the autumn of 2016 .

\section{Conclusion}

The renewed vision of multi-layered water safety focusing on protection, prevention and preparedness, extended the repertory of measures against flooding with a number of measures outside the competence of water managers. Flood risk management is now the shared responsibility of water managers and multiple other actors such as spatial planners, emergency services, insurers and, not in the least, citizens.

Because of the new collective responsibility settingup an action plan needs a different approach than before. Involving all actors from step one is necessary to come to a well-supported, committed and effective set of measures.

For this reason Flanders Environment Agency introduced the concept of river contracts. The river contract is an integrated response to the flood risk problem at catchment scale and aims at providing solutions to all affected households. It is a commitment of all actors to realize all listed measures, securing the collaborative effect.

This approach, applying multi-layered water safety to a local river catchment, combines an objective modelbased assessment with intense stakeholder deliberation resulting in a widely accepted action plan i.e. the river contract, to manage flood risk in an effective and sustainable way.

For future processes it is the intention to extend the scope of the river contract to a multi-disciplinary vision and action plan for the entire valley.

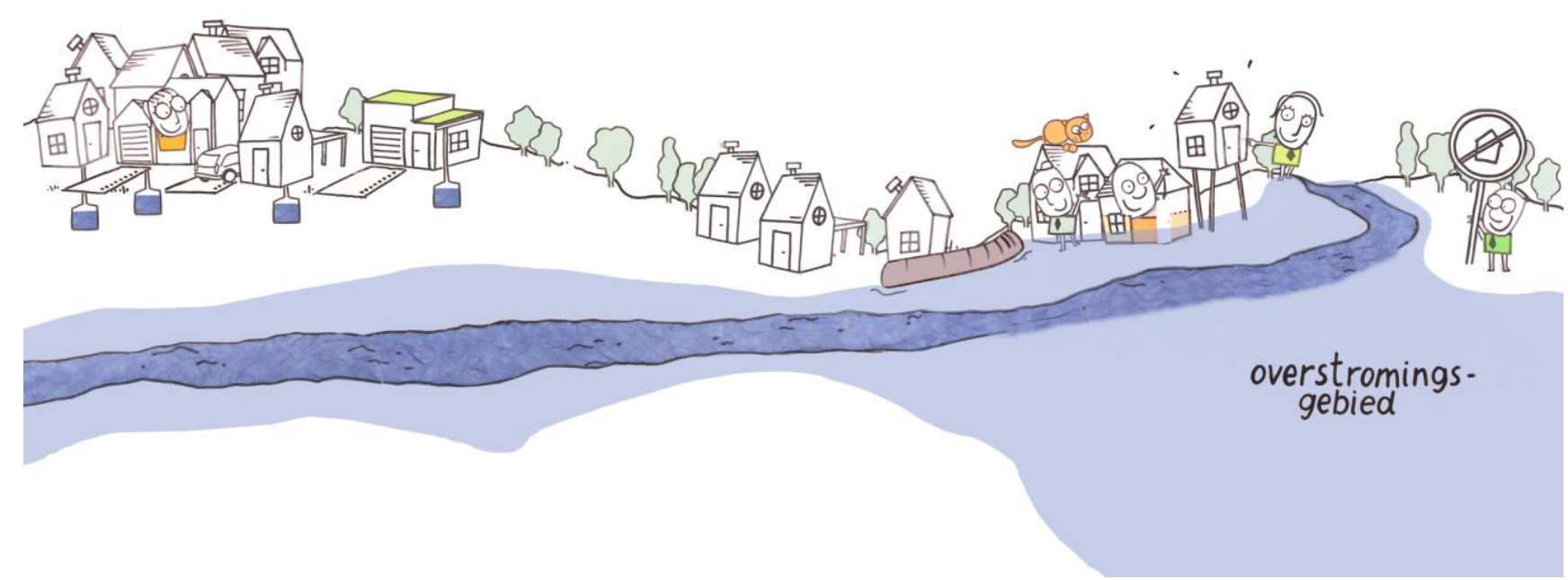

Figure 4 Illustration of the multi-layered water safety

\section{References}

1 Poelmans, L., 2010. Modelling urban expansion and its hydrological impact. Ph.D. thesis, K.U.Leuven, Faculty of Science.

2 Boukhris, O., Willems, P., Vanneuville, W., Van Eerdenbrugh, K., 2008c. Climate change impact on hydrological extremes in Flanders: Regional differences. Final report. Flanders Hydraulics Research, April 2008, 91 p.
3 Boukhris, O., 2008. Climate change impact on hydrological extremes along rivers in Flanders. Ph.D. thesis, K.U.Leuven, Faculty of Engineering.

4 Baguis, P., et al. 2010. Climate change scenarios for precipitation and potential evapotranspiration over central Belgium, Theoretical and Applied Climatology, 99(3-4), 273-286

5 Ntegeka, V., Baguis P., Boukhris O., Willems P., Roulin E., 2008. "Climate change impact on hydrological extremes along rivers and urban drainage systems. II.Study of rainfall and ETo climate change scenarios", Interim report, 
K.U.Leuven - Hydraulics Section \& Royal Meteorological Institute of Belgium, May 2008, 112.

6 Ntegeka, V., Baguis P., Roulin E., Willems P., 2013. 'Developing tailored climate change scenarios for hydrological impact assessments', Journal of Hydrology, 508,307-321.

7 Willems, P., Vrac M. 2011. 'Statistical precipitation downscaling for small-scale hydrological impact investigations of climate change', Journal of Hydrology, 402 (3-4), 193-205.

8 Blanckaert, J. et al. 2012. Stratified Sampled Synthetic Hydrographs for Flood Risk Calculations,
European conference on FLOODrisk 2012 Rotterdam.

9 Devroede, N. et al. 2012. Flood Risk Management Planning in Flanders, European conference on FLOODrisk 2012 Rotterdam.

10 River basement management plans with the integrated flood risk management plans (2015): http://www.integraalwaterbeleid.be/nl/stroomgebiedb eheerplannen.

11 Coordination Committee on Integrated Water Management, Flemish Government, Multi-layered Water Safety (2015): www.hoogwaterzonderkater.be 